\title{
Using the Chemistry of Pharmaceuticals to Introduce Sustainable Chemistry and Systems Thinking in General Chemistry
}

\author{
Thomas Holme \\ Department of Chemistry, Iowa State University, Ames, IA 50010, USA \\ E-mail: taholme@iastate.edu
}

\begin{abstract}
Introductory college chemistry courses are required by a wide range of science curricula. This fact has tended to frame the courses as places where core, fundamental ideas are taught, so that a foundation of knowledge might be called upon by students when they are in subsequent courses. Unfortunately, the preponderance of compartmentalized fundamental topics bolsters learning that has challenges in terms of transfer of knowledge to other science settings. One method that has been proposed to help alleviate this concern is to incorporate systems thinking and rich contexts that directly connect foundational chemistry ideas to larger systems. One area that shows strong potential for such efforts is the science of pharmaceuticals. Adding examples related to the chemistry of drugs, both within the large lecture setting of general chemistry and within smaller discussion groups. The role of example problems, student writing projects and group construction of systems thinking related visualizations of the context of pharmaceutical chemistry are reported.
\end{abstract}


Key Words Systems Thinking, Curriculum Development, Sustainability, Rich Context, General Chemistry

\section{Graphical Abstract}

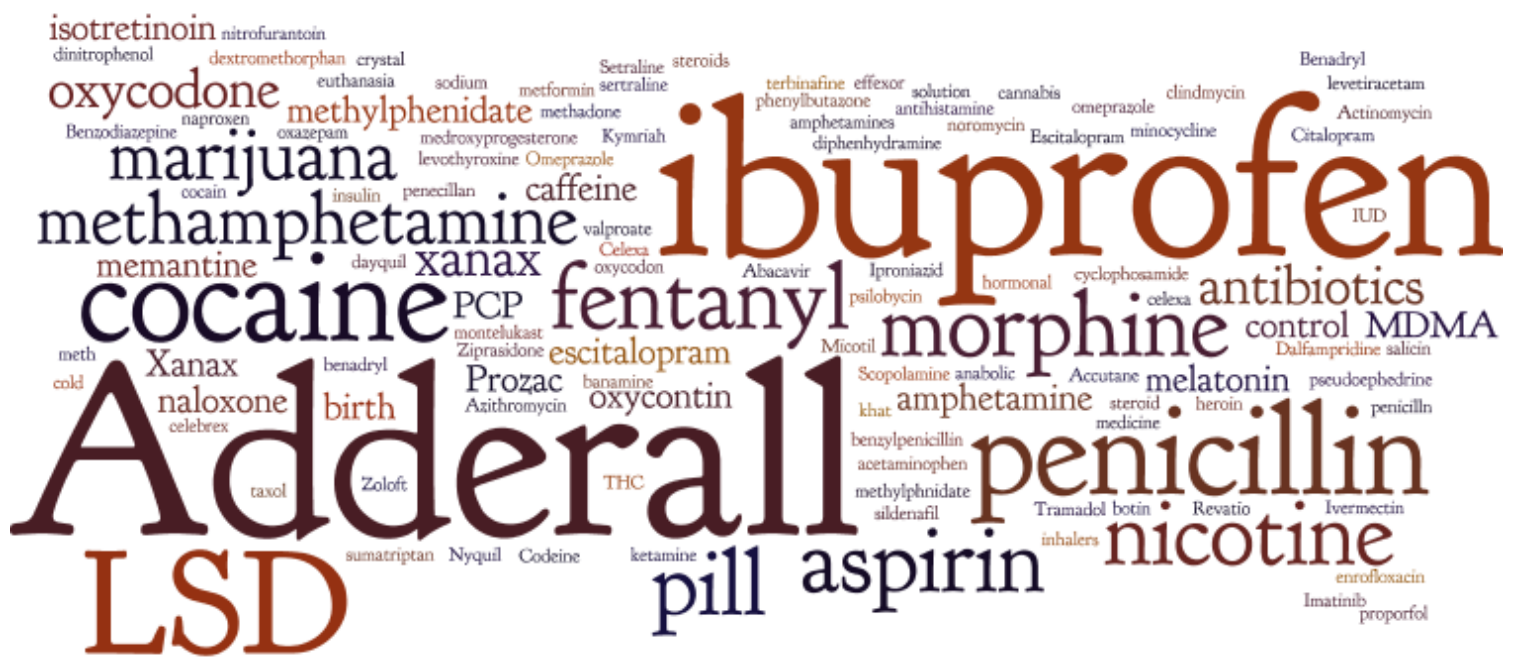




\subsection{Introduction}

Students often perceive that they enroll in introductory college science courses, such as general chemistry, in order to learn fundamental concepts. Based on the increased understanding of how people learn $(1,2)$, however, it is apparent that students often find the transfer of such fundamental knowledge to broader topics a challenge (3). Because general chemistry plays a large service roll for other science majors, this transfer challenge represents a key concern for teaching and learning in chemistry. In particular, it is vital to find ways to infuse general chemistry with enough connections to broader themes and skills to improve student knowledge transfer while maintaining appropriate attention on fundamental concepts.

Over the past few years, systems thinking has emerged as one promising way to enhance STEM education. For example in the United States, the Next Generation Science Standards (NGSS) include systems thinking and modeling as a cross-cutting concept $(4,5)$. Recently, a special issue of the Journal of Chemical Education that focused on systems thinking in chemistry education has provided a number of examples for chemistry topics that can be meshed with traditional content of the general chemistry curriculum (6-13). While these articles provided a number of practical examples of content in general chemistry connecting to larger systems, the role of chemistry in the discovery and production of pharmaceuticals was not featured as an example. It allows the consideration of life cycle analysis and ties to systems thinking, via that concept (14). The present paper seeks to provide such connections and ways they can be incorporate into a general chemistry course. 
Defining systems thinking for educational settings has been more thoroughly explored outside of chemistry (15-17), until recently(18). Ultimately, the definitions of systems thinking that are developed share similarities but are not identical. For example, educational developments in biology, engineering, environmental science and geosciences, in enumerating systems thinking work have been reviewed (19) and show subtle differences. Thus, for the purpose of this article, it is important to enumerate the aspects of systems thinking that are incorporated and to recognize that in its current implementation, not all commonly defined aspects are present.

One helpful set of traits about systems thinking has been proposed by Assaraf \& Orion (8) for geosciences education. These traits include:

Box 1: Traits of systems and systems thinking

- an ability to identify the components and the processes of a system;

- an ability to identify dynamic relationships within the system and among the system components;

- an ability to organize a framework of relationships for the system;

- an ability to understand that many systems are cyclic in nature;

- the ability to generalize outcomes of the system;

- understanding that systems may have hidden dimensions;

- an ability to use a system perspective to think temporally, including retrospection and prediction.

A refined capacity to develop and use all such traits may be more expansive than can be fostered within an already crowded curriculum in General Chemistry. Nonetheless, these traits provide a set of signposts that can help identify opportunities for incorporating some aspects of systems thinking by adding rich context examples of chemistry that is relevant to students' lives and interests. 


\subsection{Considerations of Course Design}

At many universities, General Chemistry is taken by large numbers of students, requiring multiple sections of the course. As a result, with multiple instructors participating in the teaching and learning, there are constraints on the extent to which content coverage can be adjusted, so that some level of equivalence is maintained in the multi-section course.

Given this situation, content areas in the first semester course generally include:

Box 2: First semester chemistry content in General Chemistry

- introductory material and measurements;

- balancing chemical equations and categorizing reactions;

- stoichiometry, limiting reactants, and percentage yield;

- atomic structure and periodicity;

- fundamentals of chemical bonding;

- VSEPR and assigning molecular shapes;

- relative strength of intermolecular forces;

- physical properties of gases

- energy and thermochemistry.

These foundational concepts are certainly important for students to learn, regardless of their ultimate interest in studying science. Nonetheless, they also can be covered without including direct connections to other areas of science outside of chemistry. For example, we have argued that an overarching learning outcome for the chemistry course should be that students learn the need to consider both benefits and hazards of chemicals (20). Such considerations are capable of being connected to the foundational concepts in chemistry in a number of ways. Thus, for example, the concept 
of toxicity is incorporated in our course beginning on day one, in order to promote student understanding of the risks and benefits associated with chemical systems.

Like most general chemistry courses, the chapter organization of textbook provides much of the content ordering followed in the course. Thus, while the topics may be the same or similar in any general chemistry course, the specific ordering of topics is commonly associated with the order presented in a textbook. The first semester course where the idea of drugs and their life cycle were used to introduce systems thinking components had the following content organization associated with the textbook.

\section{Box 3: Content Curriculum of First Semester General Chemistry}

1. Introduction, particles and matter

a. Includes units of measure

2. Atoms, ions and molecules

a. Includes initial introduction to the periodic table, nucleosynthesis and isotopes

3. Stoichiometry

4. Aqueous reactions / water chemistry and stoichiometry

5. Gases and their properties

6. Thermochemistry

7. Quantum model of atoms and atomic structure

a. Includes periodicity

8. Chemical bonding basics

9. Chemical bonding details and molecular geometry

10. Intermolecular Forces

a. Includes liquids and physical properties of liquids

One important feature that is used in our course to emphasize the connectedness of chemistry to other topics is referred to as tri-partite learning outcomes (21). For the first semester course, an example of this method of outlining not only the foundational ideas, but how they are known and applied is provided in Table 1. 
Table 1. Example Tripartite Learning Outcomes for $1^{\text {st }}$ Semester General Chemistry

\begin{tabular}{|l|l|l|}
\hline \multicolumn{1}{|c|}{ Knowledge: What We Know } & \multicolumn{1}{c|}{ Evidential: How We Know It } & \multicolumn{1}{c|}{ Relevance: Why It Matters } \\
\hline $\begin{array}{l}\text { Describe the role of chemistry in water } \\
\text { resources for human use and the } \\
\text { importance of water for sustainability }\end{array}$ & $\begin{array}{l}\text { Instruments (from pH, conductivity, } \\
\text { oxygen meters to chromatographic } \\
\text { instruments) and analytical techniques } \\
\text { allow purification and quality } \\
\text { measurement of water }\end{array}$ & $\begin{array}{l}\text { Water quality is directly related to human } \\
\text { health and environment. } \\
\text { Water treatment occurs both before and } \\
\text { after human use, and techniques to } \\
\text { remove chemicals depend on structural } \\
\text { characteristics of the chemicals. }\end{array}$ \\
\hline
\end{tabular}

Given this way of articulating learning outcomes, established on the first day of class, it becomes straightforward to routinely remind students in the course of the importance of how foundational ideas are connected to rich-context applications. As has been reported previously (22), in many cases these connections are to global scale societal systems such as those enumerated by the concept of planetary boundaries $(23$, 24). What is more recently implemented is the connection of general chemistry to drug molecules and the concept of life-cycle analysis of drugs (14).

\subsubsection{Incorporating pharmaceuticals and life-cycle into general chemistry}

Examples of pharmaceutical contexts that promote the "Why it matters" aspect of tri-partite learning outcomes begin early in the course. When considering units and measurement, units commonly associated with drug administration are added to those commonly described in the foundational chapter of the textbook. This section of the course also introduces small concentration units that are observed in toxicological and related research as a means for students to practice conversions within the metric system. The next occasion to connect core chemistry ideas to drug related context arises when water chemistry is covered. Traditionally, this section of the course has a strong emphasis 
on precipitation reactions. Such chemistry is included, but time is also taken to address the importance of solubility for making successful pharmaceutical agents, because of the role of aqueous chemistry in how drugs work in the body.

When topics are introduced that include pharmaceutical applications, it is important to note that students will tend to devalue their importance unless there are assessments related to them. Thus, for example, the early introduction of LD50 as a measure important for toxicity is used as an example of how chemistry routinely uses defined ratios to impart quantitative information. In the case of LD50, students can determine exposure amounts using the ratio, and judge whether enough toxic chemical is present in an assigned problem, or test question, to exceed the measured toxic limit. Such calculations complement and reinforce similar calculations early in the course using mass density, and thereby provide a means to both increase mathematical skills and the ability to make judgements about chemicals and their toxicity. This similarity is exemplified in Figure 1.

Water has a density of $0.997 \mathrm{~g} / \mathrm{mL}$ at $298 \mathrm{~K}$.
If a child's pool contains $254 \mathrm{~L}$ of water,
what mass of water is present?
$\frac{0.997 \mathrm{~g}}{1 \mathrm{~mL}} \times \frac{1000 \mathrm{~mL}}{1 \mathrm{~L}} \times 254 \mathrm{~L}=253000 \mathrm{~g}$
If the LD50 of NaF is $52 \mathrm{mg} / \mathrm{kg}$ (based on mice
studies) what mass (in $\mathrm{g}$ ) of NaF would result
in a potentially lethal dosage for a $41.5 \mathrm{~kg}$ person?
$\frac{52 \mathrm{mg}}{1 \mathrm{~kg}} \times \frac{1 \mathrm{~g}}{1000 \mathrm{mg}} \times 41.5 \mathrm{~kg}=2.16 \mathrm{~g}$

Figure 1: Example problems showing mathematical similarity between toxicology related problems and traditional general chemistry problems. 
This example points to one of the main advantages of incorporating larger systems concepts via rich contexts. As students see core concepts (in this case using a defined ratio in a calculation) implemented in more than one way, at least many of them are better equipped to use the concept behind the skill, than memorizing the algorithm of the skill. Questions such as these are also readily incorporated into test situations and thus communicate to the student that the rich contexts are fundamental components of the course.

At the same time, test questions that address only new ways to look at component skills do not really assess systems thinking itself. This area of assessment is certainly an important one (25). It is also important to recognize that testing is not the only form of assessment available to instructors. Having students write about more systems oriented circumstances in science represents another strategy, one that has been implemented for several semester, including recently with a life-cycle approach to thinking about drug molecules.

Because general chemistry is routinely taught in a large lecture setting, these writing assignments are intentionally quite short, typically 500-600 words as a maximum. The prompt is rather general, by design, so that students are not induced to think of the paper as an exercise in incorporating specific points within a strict rubric. Thus, for the Fall 2019 paper, the prompt used was:

- Choose a topic you find interesting AND capable of treating with a small word limit. The topic needs to be about:

- Any aspect of the chemistry of any drug molecule (medicinal or drugs of abuse) which can include its discovery, production, the scale of its use, the biochemistry of how it works - for good or harm, challenges related to decreased effectiveness such as drug resistance, environmental fate of the drug after disposal, etc. 
In addition to this prompt, students were explicitly instructed that in order to score well they must include at least 2 aspects of the life-cycle of the drug. It was considered appropriate that one aspect would be the primary content of the paper, but that a second component of the life-cycle had to be included. Student choices of which drug to discuss are presented as a word cloud in the graphical abstract. As is customary, the larger the word, the more commonly it was the topic of a student paper. Beyond this drug topic, Figure 2 shows the choices made by students in terms of their primary component (at the top) and their secondary component (at the bottom) of aspects of a drug life-cycle that were covered in the papers. 


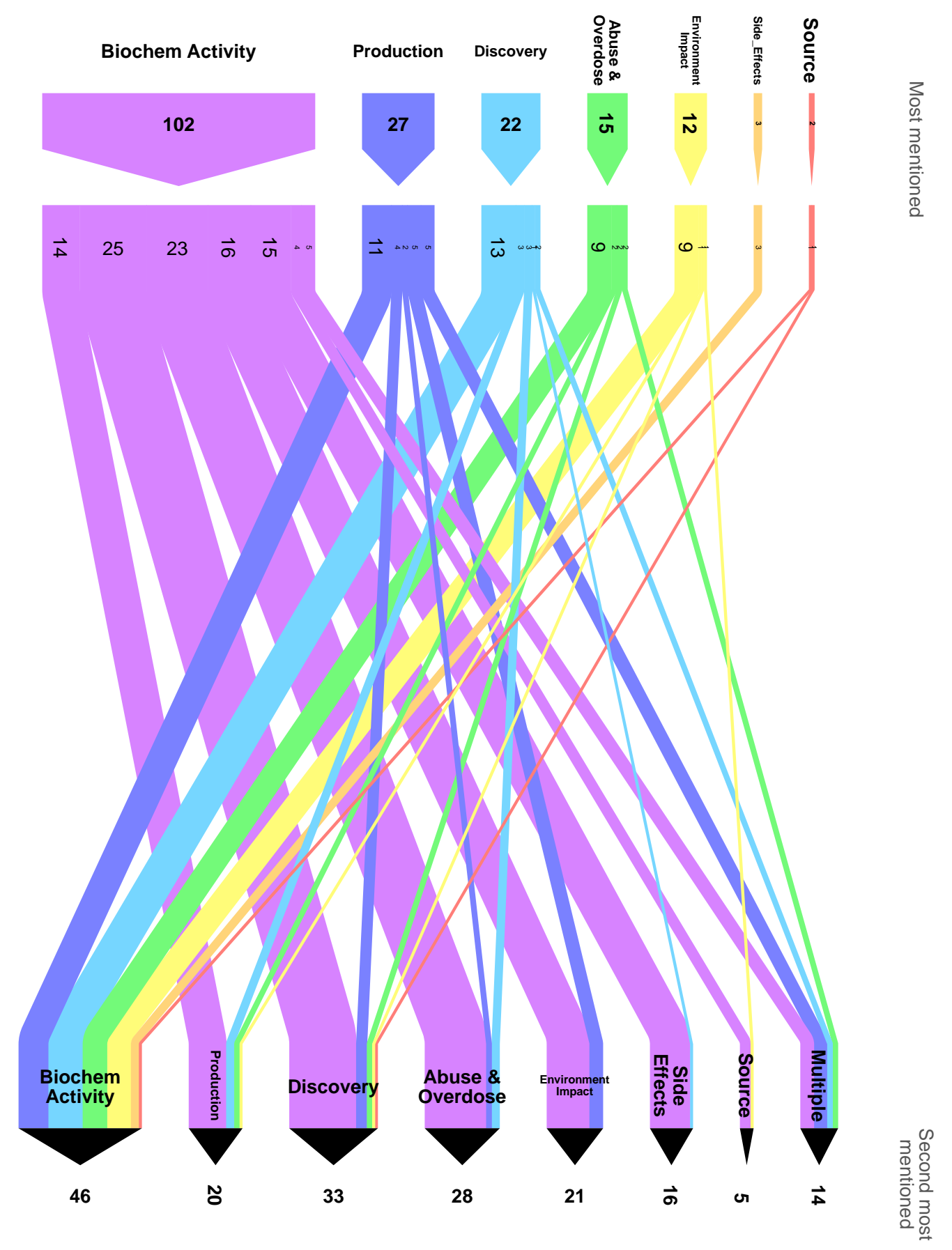

Figure 2. Aspects of drug life-cycles that comprised the primary topic (top) and secondary topic (bottom) for the drug that was described in the student papers. 
While Figure 2 is rather complex, it shows the propensities of students who have little prior exposure to thinking about drug molecules within larger systems.

Unsurprisingly, most students placed emphasis on describing the biochemical mechanisms of the drug action (102 first topic, and 46 second) as this aspect likely seems to students to be the most "chemical" of the potential discussions. What is most interesting is how framing the writing prompt in the way that was used encouraged a fairly wide range of secondary topics that were embraced by students. Given the range of choices made as the secondary topic, it is apparent that a writing assignment that requires students to consider broader aspects of a chemical and its connections to larger systems, is capable of guiding students to think about chemistry beyond the classroom-based foundational concepts commonly included in the course.

\subsubsection{Small group multi-week project}

A second form of inclusion of systems thinking related to drugs was possible by working with a small group from within the large enrollment course. This group was carrying out extra work to have the course count for credit in the University honors program. Thus, a group of 10 students held extra meetings with the course instructor. The initial session was dedicated to (a) introducing the fundamental concepts of life cycle analysis, particularly as applied to pharmaceuticals (14); and (b) identifying a candidate drug molecule to consider throughout the remainder of the sessions. In this case, the drug chosen was cytarabine.

The organizational scheme used to help visualize the connections between subsystems for the material on cytarabine as more aspects were considered is referred to as a SOCME diagram $(26,27)$. The key philosophical tenet of this visualization method is 
that it asks the question, "Are we considering the right boundary for the issue?" Thus, a concept map is extended by adding additional aspects of the problem at hand. In the sessions described here, the expanded boundaries are related to new connections between the development and use of pharmaceuticals, topics commonly taught in general chemistry and societal implications of pharmaceuticals.

The process of building out a SOCME diagram was carried out with the small discussion group over several class meetings. It began with a look at core chemistry concepts related to the drug cytarabine, and then move on to other topics. During class meetings students worked in pairs and then reported out to the class about their ideas for new aspects related to the drug, when the question of expanding the boundaries being considered was asked. The multiple suggestions from different students were then synthesized by the instructor, so that when the next class meeting was held, and expanded version of the SOCME served as the starting point, and again the question of how could the boundaries be expanded served as the goal for the subsequent activities.

A compiled version of this process is provided in Figure 3. The subsystems that were considered are color coded to provide insight into the chronology of the steps as they were taken. The first step in the SOCME production included the green-hued subsystems (Core Chemistry and Cytarabine Mimic). The second aspects that were added (Economics and Ethics subsystems) are purple-hued. The final class session added three subsystems (Biochemistry, Side effects and Cytarabine Discovery and Development) that have a yellow-hue. Had additional time been available, the class sentiment was leaning towards the next addition being how changes in the environment affect the future of discovery of naturally occurring pharmaceutical agents. This interest arose because of the 
fact that coral reefs, the original source of cytarabine, are facing increased stress due to ocean chemistry changes, but this potential boundary expansion was not completed before the semester finished.

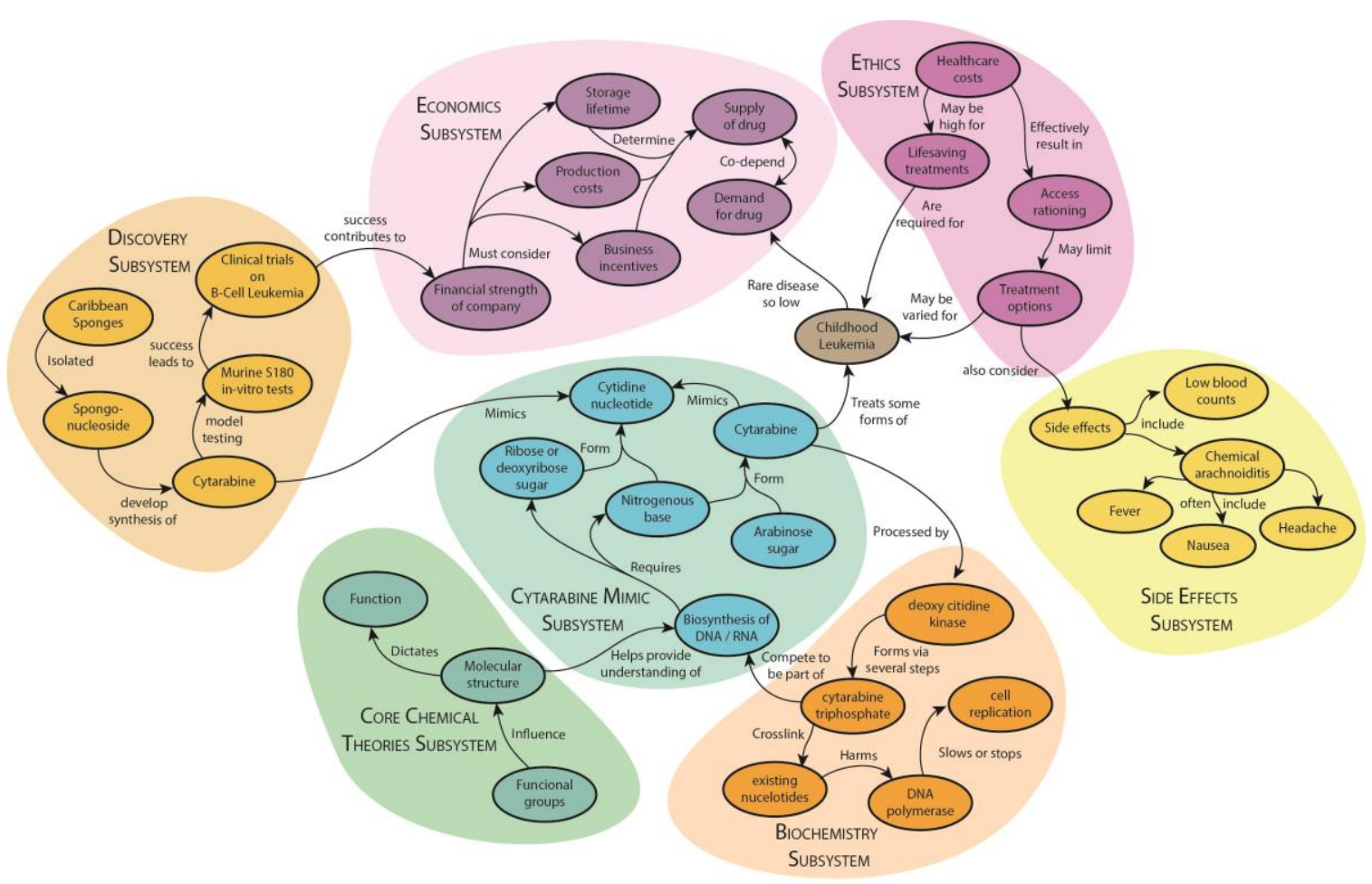

Figure 3: The SOCME diagram for the drug cytarabine, noting general chemistry principles as well as various aspects of the scientific and societal implications of the drug.

With a process like the building of a SOCME diagram, there are inevitably many options for how to proceed. With the small discussion group setting these choices were made in two ways. First, when in-class progress was more rapid for developing ideas within subsystems, it was possible to hold a discussion near the end of the class period on what topics would make sense to carry out research and expand in subsequent classes. The second way to move forward was to briefly identify several possible directions and 
let students respond to email communications about which aspects they were most interested in researching. Thus for example, looking at Figure 3, it can be seen that the second expansion of the SOCME (purple-hue) had a strong societal theme. This choice was sparked by reports that cytarabine shortages for treatments had occurred and students were interested in the way that such issues arise when science meets societal needs and constraints (28). By contrast, the three final additions (yellow-hue) describe more diverse scientific topics than the "ethics and economics" subsystems (purple-hue) which covered somewhat connected societal implications. This observation may suggest that when students are asked to explore how science is used in society, they have a more limited perspective. Given the probability that students enrolled in gateway science courses are more likely to have experienced extended science coursework than social science coursework related to societal implications of science, this tendency is perhaps predictable.

It remains important to note that student small groups did make attempts to expand the SOCME as it developed. This process was reported by them to be particularly challenging, and often they preferred to bring materials to the in-class discussion and work more collaboratively towards the next step in building the SOCME. This observation points to the importance of instructor provided scaffolding in the introduction of systems thinking concepts. It also suggests that scaling up activities like the construction of SOCME diagrams is likely to require significant instructional efforts and resources, to be carried out in the larger, whole-class setting. 


\subsection{Summary and Conclusions}

The concept of adding rich context to general chemistry is broader than incorporating systems thinking (21). Among the challenges posed by seeking to engage students in topics that lend themselves to a systems thinking approach is that they tend to have both multiple scientific aspects and complex connections to societal needs. In a course such as general chemistry, where a rather broad array of foundational concepts are the primary drivers of the curriculum, the challenge is even more substantial. Topics that can incorporate rich context also need to be capable of being clearly connected to those foundational concepts, preferably throughout the course.

The discovery, development, use (and abuse), societal implications and environmental fate of drugs represents one option where efforts to incorporate a systems thinking approach shows some promise. In the initial implementation presented here, there are essentially two levels considered. In the setting of the whole-class, and it's large enrollment, specific connections to a few foundational topics are presented. These choices are motivated largely by being able to provide additional examples of how the foundational ideas and skills are applied in science. At this level, therefore, the focus tends to be more strongly associated with bolstering the understanding students have of components that contribute to larger systems. The primary way that these components are then connected to systems and assessed is via a writing assignment that requires students to explore at least two aspects of a life cycle analysis of a drug molecule. Students are allowed to choose the drug of interest to them, and evidence from this initial implementation suggests that they find this task achievable, as an analysis of topic coverage within the corpus of student papers has shown (Figure 2). 
The ability to identify projects more suited to small groups from within the larger group setting has also been implemented. This aspect of introducing systems thinking is more capable of moving beyond the treatment of components and incorporate more varied and complex connections of chemistry an society. This has been accompanied by student participation of a SOCME diagram $(26,27)$ of a particular drug, cytarabine. Student interest was used to direct which aspects of larger systems thinking needed to be considered, and student research work was certainly capable of providing information that could usefully expand the system upon repeated queries of how the boundary being considered for the system might be expanded.

Ultimately, the use of pharmaceutical molecules to provide a context for the incorporation of more systems thinking related skills seems to be capable of promoting a high level of student interest and buy-in. General chemistry is a course taken by students with a variety of science and engineering interests. Thus, the ability to find a rich context via pharmaceuticals is particularly promising. While the interest of pre-health students seems likely to be a sure bet, this theme captured the interest of much broader set of students. For example, the need to consider the production of drugs was of notable interest to many chemical engineering students in the course. Students involved in studies related to ecology found the environmental fate of drugs to be particular interest in many cases. With the wide range of possible drug molecules available to serve as a rich context, this strategy for incorporating systems thinking into general chemistry holds significant promise and the initial implementation reported here provided several forms of evidence that supports this premise. 


\section{References}

1. How People Learn: Brain, Mind, Experience, and School: Expanded ed., 2nd ed., National Academies Press: Washington, DC, 2000.

2. How People Learn II: Learners, Contexts, and Cultures. National Academies Press: Washington, DC, 2018.

3. Taber, K.S. The Role of Conceptual Integration in Understanding and Learning Chemistry. in: Garcia-Matinez, J., Serrano-Torregrosa, E., (Eds.), Chemistry Education: Best Practices, Opportunities and Trends. Wiley-VCH, Weinheim, Germany, 2015, pp. 375-394.

4. A framework for K-12 science education: practices, crosscutting concepts, and core ideas. National Academies Press: Washington, DC, 2012.

5. Del Carlo, D.I. Crosscutting Concepts as a Framework for Professional Development in: NGSS Curriculum for High School Chemistry, ACS Symp. Ser., 1335, (2019) 67-81.

6. Constable, D.J.C., Jimenez-Conzalez, C., Matlin, S.A. Navigating Complexity Using Systems Thinking in Chemistry, with Implications for Chemistry Education. J. Chem. Educ., 96, (2019) 2689-2699.

7. Mahaffy, P.G., Matlin, S.A., Whalen, J.M., Holme, T.A Integrating the Molecular Basis of Sustainability into General Chemistry through Systems Thinking. J. Chem. Educ., 96, (2019) 2730-2741.

8. Perosa, A., Gonella, F., Spagnolo, S. Systems Thinking: Adopting an Emergy Perspective as a Tool for Teaching Green Chemistry. J. Chem. Educ., 96, (2019) 27842793.

9. Petillion, R.J., Freemann, T.K., McNeil, W.S. United Nations Sustainable Development Goals as a Thematic Framework for an Introductory Chemistry Curriculum. J. Chem. Educ., 96, (2019) 2845-2851.

10. Ginzburg, A.L., Check, C.E., Hovekamp, D.P., Sillin, A.N., Brett, J., Eshelman, H., Hutchison, J.E. Experiential Learning to Promote Systems Thinking in Chemistry: Evaluating and Designing Sustainable Products in a Polymer Immersion Lab. J. Chem. Educ., 96, (2019) 2863-2871.

11. Zowada, C., Siol, A., Gulacar, O., Eilks, I. Phosphate Recovery as a Topic for Practical and Interdisciplinary Chemistry Learning. J. Chem. Educ., 96, (2019) 29522968. 
12. Maharaj, F.D.R., Wu, W., Zhou, Y., Schwanz, L.T., Marshak, M.P. Exploring RealWorld Applications of Electrochemistry by Constructing a Rechargeable Lithium-Ion Battery. J. Chem. Educ., 96, (2019) 3014-3017.

13. Mackenzie, L.S., Tyrrell, H., Thomas, R., Matharu, A.S., Clark, J.H., Hurst, G.A. Valorization of Waste Orange Peel to Produce Shear-Thinning Gels. J. Chem. Educ., 96, (2019) 3025-3029.

14. Emara, Y., Siegert, M.-W., Lehmann, A., Finkbeiner, M. Life Cycle Management in the Pharmaceutical Industry Using an Applicable and Robust LCA-Based Environmental Sustainability Assessment Approach. in: Benetto, E., Gericke, K., Guiton, M., (Eds.), Designing Sustainable Technologies, Products and Policies, Springer, Cham, Switzerland, 2018, pp. 79-88.

15. Assaraf, O. B.-Z., \& Orion, N. Development of system thinking skills in the context of earth system education. J. Res. Sci. Teach., 42, (2005) 518-560.

16. Arnold, R. D., \& Wade, J. P. A definition of systems thinking: A systems approach. Procedia Computer Science, 44, (2015) 669-678.

17. Verhoeff, R. P., Boersma, K. T., \& Waarlo, A. J. Multiple representations in modeling strategies for the development of systems thinking in biology education. in: . D. F. Treagust, C. - Y. Tsui, (Eds.) Multiple representations in biological education. Springer, The Netherlands, 2013, pp.331-348.

18. Orgill, M., York, S., MacKellar, J. Introduction to Systems Thinking for the Chemistry Education Community. J. Chem. Educ., 96, (2019) 2720-2729.

19. Yoon, S. A., Goh, S.-E., \& Park, M. Teaching and learning about complex systems in K-12 science education: A review of empirical studies 1995-2015. Rev. Educ. Res., 88, (2018) 285-325.

20. Holme, T.A.; Hutchison, J.E. A Central Learning Outcome for the Central Science. $J$. Chem. Educ. 95 (2018) 499 - 501.

21. Mahaffy, P.G., Holme, T.A., Martin-Visscher, L., Martin, B.E., Versprille, A., Kirchhoff, M., McKenzie, L., Towns, M. Beyond "Inert" Ideas to Teaching General Chemistry from Contexts: Visualizing the Chemistry of Climate Change (VC3). J. Chem. Educ., 94 (2017) 1027-1035.

22. Holme, T.A. Incorporating elements of green and sustainable chemistry in general chemistry via systems thinking. in: A. Dicks, L. Bastin, (Eds.) Integrating Green and Sustainable Chemistry Principles into Education, Elsevier, Amsterdam, 2019, pp. 31-47.

23. Rockström, J., Steffen, W., Noone, K., Persson, Å., Chapin, III, F.S., Lambin, E., Lenton, T.M., Scheffer, M., Folke, C., Schellnhuber, H., Nykvist, B., De Wit, C.A., 
Hughes, T., van der Leeuw, S., Rodhe, H., Sörlin, S., Snyder, P.K., Costanza, R., Svedin, U., Falkenmark, M., Karlberg, L., Corell, R.W., Fabry, V.J., Hansen, J., Walker, B.H.,

Liverman, D., Richardson, K., Crutzen, C., Foley. J. A safe operating space for humanity. Nature 461 (2009) 472-475.

24. Steffen, W., Richardson, K., Rockström, J., Cornell, S.E., Fetzer, I., Bennett, E.M., Biggs, R., Carpenter, S.R., de Vries, W., de Wit, C.A., Folke, C., Gerten, D., Heinke, J., Mace, G.M., Persson, L.M., Ramanathan, V., Reyers, B., Sörlin, S. Planetary boundaries: Guiding human development on a changing planet. Science, 347 (2015) 1259855.

25. Talanquer, V. Some Insights into Assessing Chemical Systems Thinking. J. Chem. Educ., 96 (2019) 2918-2925.

26. Mahaffy, P., Matlin, S.A., Holme, T.A., MacKellar, J., Systems Thinking for Education about the Molecular Basis of Sustainability. Nature Sustainability, 2 (2019) 362-370.

27. Aubrecht, K.A., Dori, Y.J., Holme, T.A., Lavi, R., Matlin, S.A., Orgill, M., SkazaAcosta, H. J. Chem. Educ., 96 (2019) 2888-2900.

28. Drug Shortages: Root Causes and Potential Solutions. U.S. Food \& Drug Administration, Washington, DC. (Accessed at:

https://www.fda.gov/media/132059/download) 2019. 